\title{
CORRIGENDUM
}

\section{Dirac cones reshaped by interaction effects in suspended graphene}

D. C. Elias, R. V. Gorbachev, A. S. Mayorov, S. V. Morozov, A. A. Zhukov, P. Blake, L. A. Ponomarenko, I. V. Grigorieva, K. S. Novoselov, F. Guinea and A. K. Geim

Nature Physics 7, 701-704 (2011); published online 24 July 2011; corrected after print 21 December 2011.

In the version of this Letter originally published, the prefactor in equation (2) should have been $-8 / \pi^{2} N_{\mathrm{f}}$. This error has been corrected in the HTML and PDF versions of the Letter. 